\title{
O SISTEMA BRASILEIRO DE DEFESA DA CONCORRÊNCIA E A ANÁLISE DAS PRÁTICAS ENTRE CORRETORAS DE CRIPTOMOEDAS E OS BANCOS TRADICIONAIS
}

RESUMO: Analisa-se a posição do Judiciário Brasileiro e do Sistema Brasileiro de Defesa da Concorrência quanto às possíveis práticas anticoncorrenciais dos Bancos Tradicionais com relação às corretoras de criptomoedas. Objetiva destacar a necessidade de regulação do Setor Bancário e das corretoras de criptomoedas, potenciais concorrentes dos Bancos tradicionais. $\mathrm{O}$ estudo tem base na Nota Técnica $n^{\circ} .39 / 2018$ da Superintendência Geral do Cade e o julgamento de caso semelhante pelo Superior Tribunal de Justiça. Trata-se de pesquisa bibliográfica e documental para a exposição da teoria e dos dados segundo procedimento monográfico de abordagem dedutiva, utilizando o método qualitativo e a análise explicativa.

PALAVRAS-CHAVE: Setor bancário e criptomoedas; Sistema Brasileiro de Defesa da Concorrência e criptomoedas; Infrações à Ordem Econômica; Inovação e concorrência; Direito da Concorrência.

\section{THE ANTITRUST BRASILIAN SYSTEM AND THE ANALYSIS OF PRACTICES BETWEEN INITIAL COIN OFFERING (ICON)/ ALTERNATIVE COINS (ALTCOIN) BROKERS AND THE TRADITONAL BANKS}

\begin{abstract}
It's analyzed the Judiciary Brazilian's position and of the Antitrust Brazilian System referred to the possible anticompetitive practices by the Traditional Banks toward ICON brokers. Objectives point the necessity of Bank Sector's regulating and the ICON brokers too, once they're potentials traditional Bank's concurrences. This work is based on the Cade's General Superintendence Technical Note n ${ }^{\circ}$ 39/2018 and a similar case judged by the Superior Court of Justice. It's a bibliographical and documental research to exposit the theory and dates by a monographic procedure, deductive approach, qualitative method and explicative analysis.

PALAVRAS-CHAVE: Bank Sector and ICON/ALTCOIN; Antitrust Brazilian System's and ICON/ALTCOIN; Economic Order's Infractions; Innovation and competition; Competition Law.
\end{abstract}

\footnotetext{
${ }^{1}$ Bacharel em Direito pelo CESUSC e em Ciências Econômicas pela Universidade Federal de Santa Catarina. Mestranda no Programa de Pós-Graduação em Direito da Universidade Federal de Santa Catarina.

${ }^{2}$ Professor Titular da UFSC. Doutor em Direito Econômico (UFMG/MG); Doctor en Derecho Internacional Económico por la Universidad de Buenos Aires (UBA/ Bs. As.) Argentina; Mestre em Direito (UFSC/SC); Especialista em Comércio Exterior e Integração Econômica no MERCOSUL (FURG/RS); Especialista em Administração Universitária (FURG/RS); Professor credenciado no Programa de Pós-Graduação em Direito da Universidade Federal de Santa Catarina (PPGD/UFSC); Coordenador do Centro de Estudos Jurídico-Econômicos e de Gestão para o Desenvolvimento (CEJEGD).

Rev. de Direito, Economia e Desenvolvimento Sustentável | e-ISSN: 2526-0057| Goiânia| v. 5 | n. 1 | p. 57-76| 


\section{INTRODUÇÃO}

O sistema financeiro desempenha funções que são de extrema importância para o desenvolvimento de um país. Dentre as suas atribuições, destacam-se: a intermediação financeira, na qual os recursos ociosos são transferidos para o lado produtivo da economia; a oferta de ativos para diferentes perfis de risco, que possibilita a acumulação de riquezas por parte dos agentes poupadores; e a realização do sistema de pagamentos da economia, por meio de entidades, sistemas e procedimentos que são suporte às movimentações financeiras em geral. Ressalta-se que há grande necessidade de regulação deste mercado, tendo em vista que o mesmo convive com o chamado risco sistêmico, sendo imprescindível a manutenção da confiança dos agentes no sistema para a garantia de sua estabilidade. De acordo com a Organização para a Cooperação e Desenvolvimento Econômico (OCDE), a regulação do sistema financeiro não é apenas importante para evitar crises sistêmicas, mas também para proteger os consumidores e evitar abusos de poder de mercado (OCDE, 2015).

O surgimento de mercados tecnológicos está impactando diversos setores da economia e transformando as relações entre os agentes. A crescente inovação está fazendo com que novos produtos e serviços adentrem mercados já existentes, porém com diferenciais tecnológicos que colocam em risco os modelos pré-existentes. Essas mudanças estão ocorrendo especialmente no setor bancário e de serviços financeiros, nos quais é possível notar, inclusive, uma alteração no comportamento dos investidores, que, cada vez mais, se integram a essas novas tecnologias. A introdução das tecnologias disruptivas no setor financeiro reduz os custos de transação e permite uma melhora no bem-estar dos consumidores.

$\mathrm{O}$ advento das novas tecnologias no sistema financeiro, mais especificamente no setor bancário e de serviços financeiros, tem causado impactos sobre a regulação, a qual possui o desafio de englobar as recentes inovações. Contudo, percebe-se que a atual realidade é bastante dinâmica e, dia após dia, novas modificações nos produtos e serviços vão ocorrendo, o que torna difícil um acompanhamento dos órgãos reguladores frente a todas essas mudanças. É o que está ocorrendo, por exemplo, com as moedas virtuais, que são definidas pelo Banco Central do Brasil como representações digitais de valor, o qual depende da confiança depositada em suas regras de funcionamento e em sua cadeia de participantes, não sendo emitidas por nenhuma autoridade monetária. Em seu site, o Bacen deixa claro que as criptomoedas não se confundem 
com as moedas eletrônicas previstas na Lei n. 12.865/13, sendo que aquelas não são emitidas, garantidas ou mesmo reguladas pelo Banco Central. Logo, não são consideradas moedas oficiais (BACEN, 2017).

Deste modo, observa-se que a regulação não vem acompanhando as inovações tecnológicas dos últimos anos e isso se torna um problema, na medida em que os agentes econômicos, tanto do lado da oferta quanto do lado da demanda, acabam ficando sem garantias, porquanto ausente uma legislação específica regulamentar. Essa ausência de regulação não pode, no entanto, ser um empecilho para o crescimento e funcionamento destes mercados. Porém, recentemente foram observados alguns casos de fechamento de contas-correntes de corretoras de criptomoedas, por parte dos bancos tradicionais, muitos deles sob a justificativa de que referida atividade (corretagem de moedas virtuais) não possui um código específico de Classificação Nacional de Atividades Econômicas (CNAE), em razão da ausência de regulamentação da referida atividade, fato que torna impossível a identificação destas empresas como clientes dos bancos.

O presente artigo, portanto, tem como objetivo apresentar as condutas praticadas pelos bancos tradicionais frente ao aparecimento de novas tecnologias, especialmente as criptomoedas, no setor bancário e de serviços financeiros e verificar se tais atos podem ser considerados infrações à ordem econômica, à luz do art. 36 da Lei n. 12.529/11. Esta observação será realizada tendo como base a análise efetuada pela Superintendência-Geral do Cade na Nota Técnica n. 39/2018/CGAA2/SGA1/SG/CADE.

\section{TECNOLOGIAS DISRUPTIVAS E AS POSSÍVEIS REAÇÕES DAS EMPRESAS CONSOLIDADAS}

As tecnologias disruptivas são aquelas capazes de modificar o funcionamento dos mercados e que, ao mesmo tempo, fazem surgir novos modelos de negócio. Os setores bancário e de serviços financeiros se modificaram muito nos últimos anos, em razão da introdução destas novas tecnologias. Em específico, no segmento bancário, pode-se observar que as agências físicas perderam espaço para plataformas como "internet banking" e "mobile banking", que promovem maior comodidade aos consumidores, ao possibilitarem a realização de transações na hora e lugar desejados pelos mesmos. Deste modo, as tecnologias têm modificado os relacionamentos das instituições financeiras com os clientes. 
Uma pesquisa da Federação Brasileira dos Bancos (FEBRABAN) revelou que o setor bancário foi um dos que mais gastou com tecnologia no ano de 2016, conforme se verifica na figura abaixo (FEBRABAN, 2018).

Figura 1 - Composição dos dispêndios em tecnologia por setores no Brasil e no mundo em 2016 COMPOSIÇÃO DOS DISPÊNDIOS EM TECNOLOGIA POR SETORES NO BRASIL E NO MUNDO EM 2016

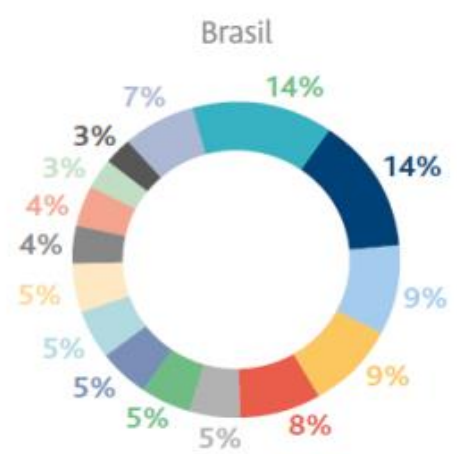

US\$ 42,9 bilhões

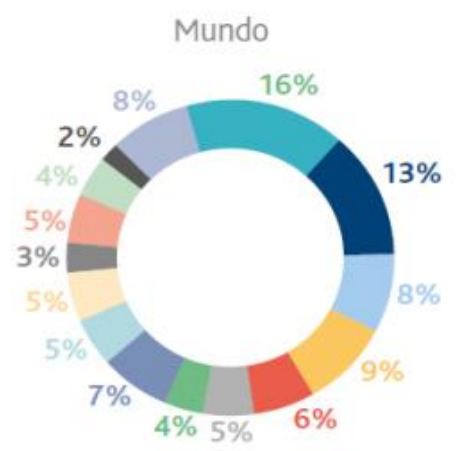

US\$ 2,7 trilhões

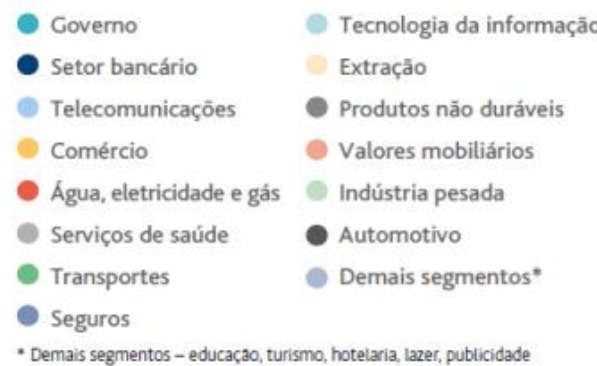

- Demais segmentos - educaçao, turismo, hotelaria, lazer, publicidade

FONTE: GARTNER

Fonte: FEBRABAN, 2018.

O gráfico acima demonstra que o setor bancário tem investido muito em tecnologias, tanto no Brasil, como no mundo. Esses investimentos têm refletido uma variedade de produtos e serviços no segmento bancário. Destaca-se, neste ambiente de inovações, o aparecimento das fintechs, que são definidas como startups atuantes na área de serviços financeiros. Atualmente, já existem fintechs de investimentos, seguros, crédito, gestão financeira, pagamentos e criptomoedas.

Com o surgimento destas inovações no mercado, no entanto, as instituições financeiras tradicionais podem sentir uma pressão competitiva e tendem a apresentar reações das mais variadas, como a compra da empresa que introduziu a nova tecnologia, por exemplo. Contudo, dentre as possíveis respostas, pode ocorrer a prática de certos atos na tentativa de excluir ou criar obstáculos aos agentes entrantes. Esses atos, porém, são considerados infrações à ordem econômica e devem ser reprimidos pela autoridade de defesa da concorrência.

No último ano, foi possível verificar uma reação dos bancos tradicionais contra as corretoras de criptomoedas. Referidos bancos têm fechado as contas-correntes das corretoras, sob as justificativas: a) de que as corretoras não tomam as medidas necessárias para evitar 
atividades ilícitas; b) de que o setor não é regulado, inexistindo uma CNAE específica para a atividade de corretagem de moedas virtuais; ou, até mesmo, c) de não haver mais interesse comercial na manutenção das contas. Em vista disso, a Associação Brasileira de Criptomoedas e Blockchain (ABCB) denunciou os fatos ao Cade alegando que os bancos estariam cometendo infrações à ordem econômica ao obstarem o acesso das corretoras de moedas virtuais ao sistema bancário, sendo este acesso essencial para o exercício das atividades das empresas (CADE, 2018).

\section{PAPEL DO CONSELHO ADMINISTRATIVO DE DEFESA ECONÔMICA}

A livre iniciativa constitui um dos fundamentos da República Federativa do Brasil e está prevista já no art. $1^{\circ}$ da Constituição Federal de 1988 (CRFB/88). De igual modo, o art. 170, inciso IV, do Diploma Constitucional estabelece a livre concorrência como um dos princípios gerais da atividade econômica. Este princípio é importantíssimo e deve ser incentivado em todo o território nacional, porquanto um mercado competitivo traz benefícios para toda a coletividade. Isso porque, havendo concorrência, as empresas precisam reduzir seus custos e constantemente buscar novas tecnologias para diversificar seus produtos e, consequentemente, atrair mais consumidores.

De acordo com Ferreira (2018), a livre concorrência garante o bom funcionamento do mercado, pois permite que os agentes que oferecem um produto melhor a um preço menor se mantenham no mercado, obtendo lucros razoáveis e estimulando novos investimentos, fato que incentiva o crescimento econômico.

Pautada na livre iniciativa, livre concorrência, função social da propriedade, defesa dos consumidores e defesa do abuso de poder econômico, a Lei n. 12.529/11 estruturou o Sistema Brasileiro de Defesa da Concorrência (SBDC), do qual o Conselho Administrativo de Defesa Econômica (Cade) faz parte juntamente com a Secretaria de Acompanhamento Econômico do Ministério da Fazenda (SEAE/MF).

O Cade é uma autarquia federal vinculada ao Ministério da Justiça que possui competência para atuar, no âmbito nacional, na análise de atos e condutas que possam contrariar a ordem econômica. Para proteger a livre concorrência o Cade utiliza-se das seguintes funções: preventiva, na qual analisa os atos de concentração e efetua consultas; repressiva, em que investiga e pune práticas contrárias à ordem econômica; e educativa, em que promove a cultura 
da concorrência, disseminando a importância de se manter um ambiente concorrencial saudável (CADE, 2016).

O presente trabalho focará na função repressiva, de investigação e punição das infrações à ordem econômica, exercida pelo Cade. Deste modo, havendo indícios de infrações a Superintendência-Geral do Cade pode promover, nos termos do art. 13, inciso III, e do art. 66 da Lei n. 12.529/11, procedimento preparatório de inquérito administrativo, para verificar se a matéria em análise é de competência do SBDC e instaurar inquérito administrativo para a apuração das infrações à ordem econômica (BRASIL, 2011).

\subsection{INFRAÇÕES À ORDEM ECONÔMICA}

Entende-se que uma empresa possui posição dominante, quando detém significativa parcela de mercado, ou seja, quando controlar $20 \%$ ou mais do mercado relevante de seu setor, conforme dispõe o $\S 2^{\circ}$, do art. 36 da Lei n. 12.529/11. Isso não quer dizer, contudo, que as empresas que detenham parcela substancial de mercado, possuem poder de mercado. O poder de mercado é caracterizado como a capacidade de determinadas empresas em manter preços acima do nível competitivo, sem perder clientes. Assim, além da posição dominante, outros fatores são essenciais para a análise do poder de mercado. Dentre eles, mostra-se necessária a verificação da existência de barreiras à entrada, de competição efetiva entre a empresa e seus concorrentes, bem como a análise acerca das possibilidades de importações. O poder de mercado não é ilegal, todavia, utilizá-lo para práticas anticompetitivas configura-se abuso de poder econômico (CADE, 2019).

De acordo com Figueiredo (2012, p. 260), diagnosticar o abuso de poder econômico é uma tarefa difícil que requer conhecimentos técnicos, especialização e prática profissional. Segundo o autor, diversas são as condutas que podem se traduzir em infrações à ordem econômica, pois a mera existência de potencial efeito danoso ao mercado já é suficiente para a sua caracterização. Assim, as condutas apresentadas pela lei estão compreendidas em um rol exemplificativo, sendo que demais práticas não previstas na lei, mas que causem prejuízos à concorrência ou ao funcionamento do mercado, podem também ser caracterizadas como infrações à ordem econômica.

Figueiredo (2012, p. 260) continua, definindo abuso de poder econômico, nos seguintes termos: 
Por abuso de poder econômico podemos entender todo ato de agente econômico que, valendo-se de sua condição de superioridade econômica, atua prejudicando a concorrência, o funcionamento do mercado ou, ainda, aumentando arbitrariamente seus lucros. Tal conduta se perfaz nas hipóteses em que o agente, que detém substancial parcela do mercado, atua em desconformidade com sua finalidade social colimada pela legislação, cerceando a liberdade de mercado ou a livre-iniciativa. Observe-se que tal conduta se faz danosa tanto para a ordem econômica quanto para os consumidores, sendo proibida pelo ordenamento jurídico brasileiro, configurando, em verdade, exercício abusivo do direito de livre-iniciativa e de propriedade,

O abuso de poder econômico é danoso tanto para a livre concorrência, quanto para os consumidores. Deste modo, o Cade atua na repressão destas práticas anticompetitivas, analisando as condutas que possam representar infrações à ordem econômica.

A Lei n. 12.529/11 apresenta em seu art. $36^{3}$ algumas práticas restritivas, que pelo seu objeto ou pelos efeitos produzidos, representam infrações à ordem econômica. A Lei cita os seguintes efeitos anticoncorrenciais: limitar, falsear ou prejudicar a livre concorrência ou a livre iniciativa de qualquer forma; dominar mercado relevante; aumentar arbitrariamente os lucros; e exercer posição dominante de forma abusiva. O parágrafo $1^{\circ}$, do artigo supracitado deixa claro que, quando uma empresa conquista o mercado por ser mais eficiente que outras, ou seja, por métodos naturais, isto não é caracterizado como ilícito. O parágrafo $2^{\circ}$ explica o que é posição dominante, sendo a mesma presumida quando uma empresa ou grupo de empresas consigam alterar unilateral ou coordenadamente as condições de mercado, ou quando controlar $20 \%$ ou mais do mercado relevante do seu setor. Por sua vez, o parágrafo $3^{\circ}$ elenca, em um rol exemplificativo, condutas que podem ser caracterizadas como infrações à ordem econômica (BRASIL, 2011).

A prática de limitar, falsear ou prejudicar a livre concorrência ou a livre iniciativa refere-se ao impedimento ou dificuldade de entrada criada pelos agentes que já operam naquele mercado contra os possíveis entrantes, ou, ainda, a atuação no sentido de obstar a permanência de determinando agente no respectivo mercado. O domínio de mercado relevante de bens ou serviços, por sua vez, representa a imposição arbitrária da vontade de um agente aos demais, em razão da sua atuação como monopolista, na intenção de excluir os competidores. Já o aumento arbitrário dos lucros, como o próprio nome já diz, ocorre quando há uma elevação dos

\footnotetext{
${ }^{3}$ Art. 36. Constituem infração da ordem econômica, independentemente de culpa, os atos sob qualquer forma manifestados, que tenham por objeto ou possam produzir os seguintes efeitos, ainda que não sejam alcançados: I - limitar, falsear ou de qualquer forma prejudicar a livre concorrência ou a livre iniciativa; II - dominar mercado relevante de bens ou serviços; III - aumentar arbitrariamente os lucros; e IV - exercer de forma abusiva posição dominante.
} 
lucros sem que haja uma justificativa para tal ato. Por fim, o agente que exerce posição dominante de forma abusiva é aquele que detém alta concentração do mercado, fato que o coloca em posição vantajosa frente aos demais e possibilita que o mesmo imponha sua vontade aos outros agentes. Os atos que produzam os efeitos acima expostos são caracterizados como infrações à ordem econômica, na medida em que violam a livre competição (FIGUEIREDO, 2012, p. 270-271).

No caso do encerramento de contas das corretoras de criptomoedas, a denúncia realizada pela $\mathrm{ABCB}$ foi fundamentada no art. 36, incisos I, II e IV, da Lei n. 12.529/11, sendo requerida, portanto, a condenação dos bancos em razão do cometimento de infrações à Ordem Econômica. O procedimento preparatório foi instaurado e, por meio da Nota Técnica $n^{\circ}$. 39/2018/CGAA2/SGA1/SG/CADE, a Superintendência-Geral do Cade sugeriu a instauração de inquérito administrativo para melhor apuração dos fatos, tendo em vista a existência de indícios de que os bancos tenham praticado condutas anticompetitivas:

\begin{abstract}
Por ora, esta SG entende que a instrução realizada confirmou possibilidade levantada pela representante de que os bancos representados podem estar utilizando de seu poder de mercado para, em conjunto, limitar ou prejudicar a atuação das corretoras de criptomoeda, vedando o acesso desses agentes ao mercado bancário. Fatos revelados neste procedimento preparatório podem, em tese, constituir indícios de infração à ordem econômica, matéria de competência desta autarquia antitruste. Sendo assim, tem-se condições suficientes para a abertura de Inquérito Administrativo para a continuidade da investigação a respeito das práticas relatadas na denúncia e ao longo da instrução (CADE, 2018).
\end{abstract}

A seguir serão detalhados os argumentos das partes, bem como as razões pelas quais o Cade optou pela continuidade das investigações.

\title{
3.2 NOTA TÉCNICA No 39/2018/CGAA2/SGA1/SG/CADE
}

Em 07 de junho de 2018, a Superintendência-Geral do Cade, após recebimento de denúncia realizada pela $\mathrm{ACBC}$, decidiu instaurar procedimento preparatório para investigar supostas infrações à ordem econômica, relacionadas ao fechamento de contas-corrente das corretoras de criptomoedas por parte dos bancos tradicionais. Tal fato estaria impedindo ou criando dificuldades para o acesso das corretoras ao sistema bancário.

A denúncia tratou especificamente do fechamento da conta corrente da corretora Atlas Proj Tecnologia Ltda., por parte do Banco do Brasil, o qual, segundo a ABCB, não apresentou os motivos que o levaram a encerrar a conta, declarando apenas que se tratava de uma decisão 
administrativa do próprio banco. A associação afirmou, ainda, que seria impossível para a corretora continuar exercendo a sua atividade empresarial sem uma conta corrente, por tratarse de uma infraestrutura essencial. Deste modo, em razão dos empecilhos criados ao acesso ao sistema financeiro, a $\mathrm{ABCB}$ requereu a condenação do Banco do Brasil, pela prática de condutas anticompetitivas, com base nos incisos I, II e IV, do art. 36, da Lei n $^{\mathbf{o}}$ 12.529/2011 (CADE, 2018).

Um dos argumentos trazidos pela $\mathrm{ABCB}$ foi o de que há diversos casos semelhantes envolvendo outros bancos, fintechs e corretoras de moedas virtuais. A representante das criptomoedas alegou que as corretoras, por ofertarem produtos e serviços financeiros, bem como por serem meios de pagamento alternativos, são consideradas concorrentes das instituições financeiras tradicionais. Por isso, o comportamento dos bancos, que detém posição dominante no mercado, seria uma reação à concorrência das corretoras e fintechs, as quais operam com "custos mais baixos e serviços mais dinâmicos", colocando em xeque o modelo tradicional (CADE, 2018).

Vários Bancos foram oficiados pela Superintendência-Geral do Cade e apresentaram respostas, momento em que expuseram os motivos que os levaram a proceder ao encerramento das contas. Dentre os argumentos expostos pelos bancos, destaca-se: a) a impossibilidade de identificação das corretoras de criptomoedas na lista de clientes, tendo em vista a ausência de uma CNAE específica para a referida atividade; b) a inexistência de precaução por parte das corretoras para evitar atividades ilícitas; e c) a não consideração das corretoras como suas concorrentes (CADE, 2018).

Por sua vez, as corretoras, representadas pela $\mathrm{ABCB}$, afirmaram que o acesso ao sistema financeiro, por meio das contas-correntes é elemento indispensável para a continuidade de suas atividades e que sem esta infraestrutura essencial a sobrevivência e crescimento das mesmas se tornariam inviáveis (CADE, 2018).

A seguir, analisam-se os argumentos expostos pelas partes, em concordância com o que foi discorrido na Nota Técnica n. 39/2018/ CGAA2/SGA1/SG/CADE.

\subsubsection{Argumento das corretoras de criptomoedas}


As corretoras alegam que sem o acesso às contas correntes elas ficariam impossibilitadas de exercer as suas atividades. Deste modo, o principal argumento das corretoras de moedas virtuais está relacionado com a teoria da infraestrutura essencial.

A teoria da infraestrutura essencial refere-se a uma situação em que determinada empresa não consegue competir no mercado, caso não tenha acesso a um bem específico, o qual seria indispensável para a sua atuação. No caso das corretoras, as contas-correntes que as mesmas mantêm com os bancos representam insumos essenciais para a realização de suas atividades como intermediadoras de moedas virtuais. Logo, o encerramento destas contas pode refletir negativamente em seus negócios.

Essa teoria é bastante utilizada nos casos em que os mercados são altamente concentrados e, na maioria das vezes, sua aplicação ocorre em contextos nos quais existem monopólios, sejam eles naturais ou não. O conceito de infraestrutura essencial apresenta-se, então, como oposição às práticas anticompetitivas tais como a recusa de contratação e a discriminação dos agentes que necessitam do bem.

Os bens essenciais, em grande parte das vezes, são controlados por monopolistas, os quais não querem perder a sua posição dominante no mercado e o poder que detêm de controlar os preços. Contudo, como explicado anteriormente, o exercício abusivo de posição dominante, bem como a prática de atos com a finalidade de limitar a livre concorrência de qualquer forma e de manter o domínio de mercado relevante, constituem infrações à ordem econômica, estando os praticantes sujeitos às penalidades cabíveis nestes casos.

De acordo com a Ministra Nancy Andrighi do Superior Tribunal de Justiça (STJ), embora esta teoria ter sido bastante aplicada para infraestruturas físicas, atualmente percebe-se que outros bens, tais quais a propriedade intelectual e o sistema de pagamentos, são considerados essenciais para a manutenção de um ambiente competitivo. Nancy destaca que as contas correntes integram o sistema de pagamentos e que o acesso compulsório, através da obrigação de contratar, seria uma alternativa para a solução do problema concorrencial (STJ, 2018).

Deste modo, o serviço de corretagem de criptomoedas, assim como a totalidade das atividades comerciais, depende de um sistema financeiro abrangente para a sua sobrevivência. Resta clara, portanto, a possibilidade de aplicação da teoria da infraestrutura essencial ao caso analisado no presente artigo. 


\subsubsection{Defesa dos Bancos tradicionais}

Os três argumentos expostos a seguir foram os apresentados em defesa dos Bancos tradicionais, após serem oficiados pelo Cade, quais sejam: 1) a ausência de medidas para evitar atividades ilícitas; 2) a inexistência de regulação e CNAE específica para a atividade de criptomoedas e, finalmente, 3 ) a concorrência entre Bancos e corretoras de moedas virtuais. É o que se passa a tratar.

\subsubsection{Ausência de medidas para evitar atividades ilícitas}

A maior parte dos Bancos oficiados pelo Cade justificou ter encerrado as contas das corretoras, em função das mesmas não adotarem medidas preventivas para evitar atividades ilícitas. Por se sujeitarem à regulação do Banco Central do Brasil, eles precisam seguir as regras e recomendações emanadas pelo órgão, caso contrário podem incorrer nas penalidades previstas em lei. Deste modo, verificados indícios de crimes de lavagem de dinheiro, como uma movimentação de recursos incompatível com a atividade e com a capacidade financeira dos clientes, as instituições financeiras encerram as contas-correntes, até como uma forma de se prevenirem da aplicação das penalidades impostas pelo Bacen (CADE, 2018).

De fato, o Banco Central do Brasil tem como um dos seus objetivos principais a manutenção da estabilidade do Sistema Financeiro Nacional. Para isso, ele dispõe de instrumentos de regulação sistêmica e prudencial, sendo o responsável por autorizar ou não o funcionamento das instituições financeiras e podendo, inclusive, intervir nas mesmas ou declarar a sua liquidação extrajudicial. Ainda, para manter a solidez do sistema, a autoridade reguladora central tem como foco a prevenção à lavagem de dinheiro e financiamento ao terrorismo (BACEN, 2019).

Os Bancos devem se adequar aos Acordos de Basileia, respeitando as exigências de capital mínimo e controle de riscos e enviar periodicamente informações ao Bacen. Constitui um dos princípios publicados pelo Comitê da Basileia que os órgãos supervisores se assegurem de que "os bancos adotem políticas e processos adequados, incluindo regras rígidas do 'conheça seu cliente', que promovem elevados padrões éticos e profissionais no setor financeiro e impeçam que a instituição seja utilizada, intencionalmente ou não, para atividades criminosas" (CANDELORO, 2012, p.173). 
Desta forma, um dos papeis do Banco Central é fiscalizar o sistema financeiro e exigir dos bancos o cumprimento e adequação às regras, como a implementação dos controles de prevenção à lavagem de dinheiro e financiamento ao terrorismo. Observadas práticas suspeitas que possam configurar os crimes de lavagem ou ocultação de bens, direitos e valores, previstos na Lei n. 9.613/98, o Bacen poderá comunicar o fato ao Conselho de Controle de Atividades Financeiras (Coaf), ao Ministério Público, à Secretaria da Receita Federal e aos demais órgãos que combatem referidos crimes (BACEN, 2019).

A fim de consolidar as regras sobre os procedimentos de prevenção e combate aos crimes de lavagem de dinheiro, o Banco Central editou a Circular n. 3.461/09, na qual constam as diretrizes a serem adotadas pelos bancos, a fim de evitar o seu envolvimento com atividades ilícitas. A ausência destas políticas preventivas faz com que as instituições bancárias não estejam protegidas de receber recursos de origens ilegais, podendo ser penalizadas pelo regulador e ter sua imagem comprometida. As penas impostas pelo Bacen vão desde advertências, multas até proibições para atuar (CANDELORO, 2012).

Nos últimos anos, houve uma expansão dos métodos utilizados para a ocultação de bens e valores. Isso ocorreu porque os avanços tecnológicos permitiram que diversas transações pudessem ser realizadas simultaneamente, dificultando o rastreamento dos recursos. Além disso, o surgimento de novos produtos e serviços financeiros, sem a criação de regras claras e bem definidas sobre os mesmos, facilita a ação dos lavadores de dinheiro, posto que a ausência de supervisão e regulação das novas atividades reduz a probabilidade de rastreamento das origens dos recursos (CANDELORO, 2012).

Esse é o caso das criptomoedas, tendo em vista a possibilidade que os agentes que operam com essas moedas têm de realizar transações de forma anônima. Assim, dada a dificuldade de rastrear os seus usuários, as operações com moedas virtuais são bastante questionadas, pois frequentemente são utilizadas para fins ilícitos, como a lavagem de dinheiro e o financiamento ao terrorismo.

A justificativa dada pelos Bancos tradicionais ao Cade, para o fechamento das contas das corretoras de criptomoedas, foi justamente a inobservância que as mesmas possuem quanto às regras de prevenção à lavagem de dinheiro. Portanto, segundo os bancos, no momento em que são observadas movimentações de recursos de forma incompatível com o patrimônio, a atividade econômica e a capacidade financeira do correntista, fato que configura indício da 
ocorrência dos crimes de lavagem e ocultação de bens, direitos e valores, conforme a Carta Circular n. 3.542/12, art. $1^{\circ}$, inciso IV, do Bacen, eles decidem encerrar as contas.

O posicionamento, bastante adequado, adotado pela Superintendência Geral do Cade é o de que, antes de proceder ao encerramento das contas, os bancos deveriam analisar individualmente as medidas e o nível de compliance que cada corretora, individualmente, possui. Não há como aplicar as mesmas medidas (cancelamento das contas) a diferentes corretoras, como se a própria atividade de corretagem de criptomoedas se tratasse de ilícito per $s e$. Desta feita, para a conclusão do caso será necessário verificar se as corretoras têm seguido as normas e procedimentos de prevenção a crimes, como as políticas de aceitação de clientes (CADE, 2018).

Importante destacar, ainda, que existem diversos negócios alternativos no Sistema Financeiro Nacional e que também são alvos de lavadores de dinheiro, criminosos que atuam no "mercado negro", dentre outros. Vale citar, aqui, como explanado pela Ministra Nancy Andrighi, em seu voto vista no Recurso Especial n. 1.696.214/SP, que grandes empresas e empreiteiras envolvidas em escândalos de corrupção, investigadas pela Operação Lava Jato, não tiveram suas contas encerradas pelos bancos unilateralmente. Deste modo, a Ministra concluiu seu voto afirmando que, sabendo da imprescindibilidade do uso das contas-correntes para a continuidade das atividades econômicas das corretoras de moedas virtuais, os bancos extrapolaram os limites que tinham de rescindir unilateralmente os contratos, configurando-se, assim, o abuso de direito (STJ, 2018).

\subsubsection{Inexistência de regulação e CNAE específica para a atividade de criptomoedas}

Grande parte das Instituições Financeiras oficiadas respondeu que a atividade de corretagem de criptomoedas não possui uma CNAE definida, e que, portanto, não haveria como fazer discriminação entre estas e os demais clientes dos Bancos.

Diversos desafios devem ser enfrentados para o uso efetivo das moedas virtuais. Um dos maiores problemas visualizados é que, diferentemente das moedas tradicionais, o Banco Central não regula a emissão de criptomoedas, não havendo nenhuma garantia de sua conversão para moedas soberanas. Consequentemente, as moedas virtuais poderiam enfraquecer a atuação do Bacen na realização de políticas monetárias. Além disso, o preço desses ativos possui a característica de ser altamente volátil, podendo causar perdas patrimoniais enormes aos seus 
detentores, os quais devem suportar os riscos. A questão principal, contudo, é que as criptomoedas não são reguladas ou supervisionadas pelo Banco Central do Brasil, que pronunciou no Comunicado n. 31.379/17 que "embora as moedas virtuais tenham sido tema de debate internacional e de manifestações de autoridades monetárias e de outras autoridades públicas, não foi identificada, até a presente data, pelos organismos internacionais, a necessidade de regulamentação desses ativos", posto que, até aquele momento, não foram observados riscos relevantes para o Sistema Financeiro Nacional (BACEN, 2017).

Por ainda não existir uma regulação para as moedas virtuais, a atividade de corretagem das mesmas não possui uma Classificação Nacional de Atividades Econômicas (CNAE). O principal objetivo desta classificação é padronizar a identificação das unidades produtivas atuantes no país. Todavia, necessário destacar que a ausência de uma regulação ou de uma CNAE específica não pode ser um empecilho para a continuidade da oferta de produtos e serviços das empresas. Agentes inovadores não podem ser prejudicados pela inexistência de regulação, pois isso restringiria e desestimularia a própria inovação, o que vai de encontro ao Preceito Constitucional da promoção da livre iniciativa. Neste sentido, a Superintendência Geral do Cade (2018) analisou a matéria, nos seguintes termos:

[...] a falta de uma classificação própria e de regulamentação de um setor não o torna ilícito. O mercado de corretagem de criptomoedas é um mercado novo e é natural que decorra um lapso temporal entre o surgimento de novos mercados e sua regulamentação. É até lógico que o mercado se antecipe ao Estado, e não o contrário, e que, portanto, inovações, pela simples razão de trazerem consigo um caráter de ineditismo recebam presunção de licitude, decorrência natural do princípio da legalidade, previsto no artigo $5^{\circ}$, II, da Constituição Federal. Ademais, a ausência de regulamentação em hipótese alguma deve servir de argumento para tolher a livre iniciativa $[\ldots]$.

Sendo assim, e considerando a liberdade de exercício de qualquer atividade econômica, independentemente de autorização dos órgãos públicos, prevista no parágrafo único do art. 170 da CRFB/88, não é possível excluir as corretoras de criptomoedas do mercado, em razão da inércia do poder público em regular esta atividade econômica.

\subsubsection{Concorrência entre bancos e corretoras de moedas virtuais}

Muitos dos bancos tradicionais oficiados pelo Cade disseram que não consideram as corretoras de criptomoedas suas concorrentes, motivo pelo qual não seria estariam cometendo infrações à ordem econômica por restringirem o acesso de concorrentes ao mercado. No 
entanto, uma das funções exercidas pelos bancos é a oferta de alternativas de produtos financeiros, adequados para cada tipo de risco que o investidor está disposto a assumir. Quanto às criptomoedas, verifica-se, hoje, que a sua maior utilização está relacionada a investimentos, ou seja, as pessoas compram essas moedas na expectativa de auferir lucros futuros, arcando com os riscos da desvalorização da moeda e com as possíveis perdas patrimoniais. Deste modo, verifica-se que a compra de moedas virtuais pode sim ser considerada outra forma de investimento e concorrente a umas das atividades dos bancos. Destaca-se que a própria Receita Federal equipara as criptomoedas a ativos financeiros, para fins de declaração do Imposto de Renda.

De acordo com a definição de Stella (2019), as criptomoedas são ativos digitais denominados na própria unidade de conta, sendo transacionadas de forma descentralizada, ou seja, sem a necessidade de intermediários financeiros. As transferências são realizadas por uma rede distribuída de registros, sendo que os dados são assegurados por tecnologia criptográfica e por meio do consenso dessa rede. Deste modo, ainda que não se queira admitir, a dispensabilidade de intermediários financeiros proporcionada pelas criptomoedas pode afetar a função dos bancos tradicionais de intermediadores.

Além disso, deve-se ressaltar que as moedas virtuais não se caracterizam apenas pela sua representação digital de valor, mas também pela possibilidade de uso como meio de pagamento. Atualmente, verifica-se que a utilização das criptomoedas como forma de pagamento ainda é restrita. No entanto, de acordo com a Forbes, o número de estabelecimentos que aceitam as moedas virtuais está crescendo. A necessidade de inovação está fazendo com que as empresas busquem por meios que atraiam a atenção dos clientes, dentre eles o pagamento através das moedas virtuais. Empresas que aderiram à novidade afirmaram que o anúncio da aceitação de criptomoedas aumentou a fidelização da marca e a procura por seus produtos e serviços, inclusive entre estrangeiros (MANZONI, 2018).

Deste modo, as criptomoedas podem ser consideradas concorrentes dos bancos, abrangendo aqui, ainda, a concorrência potencial no caso de sua utilização como meio de pagamento.

A fim de realizar contraponto aos argumentos expostos até aqui, a seguir será apresentado o desfecho dado pelo Superior Tribunal de Justiça, ao julgar caso semelhante sobre o fechamento das contas correntes das corretoras de moedas virtuais. 


\section{JULGAMENTO DO CASO PELO STJ}

Caso semelhante envolvendo o Mercado Bitcoin Serviços Digitais Ltda. e o Banco Itaú Unibanco S/A chegou ao Superior Tribunal de Justiça. Porém, o Judiciário apresentou desfecho diferente à questão, não tratando o caso como matéria concorrencial, conforme será visto adiante.

O Recurso Especial n ${ }^{\circ}$ 1.696.214/SP foi interposto pelo Mercado Bitcoin Serviços Digitais Ltda., sob a justificativa de que o Banco Itaú Unibanco S/A estava cometendo ato ilícito e práticas abusivas ao rescindir unilateralmente o contrato de conta corrente estabelecido entre as partes. O caso foi julgado pelo STJ em outubro de 2018, sendo que a maioria dos Ministros acompanhou o voto do relator Marco Aurélio Bellizze, no sentido de negar provimento ao recurso, tendo em vista a possibilidade de "encerramento do contrato de conta de depósitos, por iniciativa de qualquer das partes contratantes, desde que observada a comunicação prévia". No caso dos autos, houve a notificação antecipada acerca do encerramento da conta (STJ, 2018).

Por outro lado, a Ministra Nancy Andrighi foi a única a proferir voto a favor da manutenção da conta corrente. Em seu voto vista, a Ministra entendeu que a conta corrente da corretora de criptomoedas seria um insumo essencial para a realização de suas atividades, sendo impossível a empresa competir ou se manter ativa no mercado sem ter uma conta corrente. Deste modo, a Ministra concluiu que o Banco cometeu abuso de direito ao negar o acesso a uma infraestrutura essencial para as atividades do Mercado Bitcoin, votando, portanto, a favor da manutenção da conta corrente em funcionamento. (STJ, 2018).

No teor de seu voto a Ministra afirmou que caberia ao STJ analisar o caso à luz da Lei n. 12.529/11, contudo, não houve prequestionamento da matéria nas primeiras instâncias. Além disso, para concluir acerca de eventual infração à ordem econômica, seria necessária a ampla investigação dos fatos, o que não ocorreu na hipótese. Assim, tendo em vista a gravidade dos fatos alegados, a Ministra Nancy Andrighi recomendou o encaminhamento da cópia do julgamento do caso ao Cade para a apuração da suposta infração à ordem econômica.

Além deste encaminhamento, a Associação Brasileira de Criptomoedas e Blockchain (ABCB) já havia realizado denúncia ao Cade em face do Banco do Brasil S.A., Banco Bradesco S.A., Banco Itaú Unibanco S.A., Banco Santander S.A., Banco Inter S.A. e Banco Sicredi 
destacando as supostas práticas contrárias à concorrência por parte destes Bancos (CADE, 2018).

Nota-se que em nenhum momento do voto do Relator foi apresentada a questão da concorrência. Após todos os argumentos até aqui expostos, fica claro que o caso merece atenção da Autoridade Concorrencial, sendo acertada a decisão da Ministra Nancy Andrighi em encaminhar cópia do julgamento ao Cade para apuração das supostas práticas anticompetitivas.

\section{CONCLUSÃO}

A livre iniciativa e a livre concorrência são dois Princípios garantidos Constitucionalmente e que são essenciais para incentivar o surgimento de inovações. Em mercados competitivos, os agentes se empenham para ofertar os melhores produtos e serviços a um preço mais baixo, a fim de atrair consumidores e se manter no mercado. Para diversificar seus produtos, as empresas investem em tecnologia, a qual impacta e modifica as relações entre os agentes econômicos.

O setor bancário é um dos que mais investe em tecnologia, tanto no Brasil, quanto no mundo. Contudo, neste ambiente de inovações, as mudanças ocorrem muito rápido, de modo que os Órgãos reguladores não conseguem acompanhar o ritmo acelerado de surgimento de novos produtos e serviços financeiros. É o que ocorre com as criptomoedas, as quais não são emitidas, tampouco reguladas ou supervisionadas pelo Banco Central do Brasil.

Frente ao aparecimento de novas tecnologias financeiras, alguns agentes já estabelecidos no mercado tendem a apresentar certas atitudes, como a aquisição das empresas inovadoras que estão ingressando no mercado ou até mesmo a manifestação de reações contrárias à entrada das mesmas no setor. Determinadas atitudes, contudo, podem ser consideradas infrações à Ordem Econômica, na medida em que limitam a livre concorrência.

Neste sentido, o presente artigo tratou sobre a conduta recente de determinados Bancos tradicionais, na tentativa de verificar se os mesmos seriam concorrentes das corretoras de criptomoedas e se a reação que tiveram de fechamento das contas-correntes pode ser considerada um indício de prática anticompetitiva.

Observou-se que as corretoras de criptomoedas possuem uma atividade comum à dos Bancos, na medida em que ofertam produtos de investimento de alto risco. Ademais, a crescente utilização das moedas virtuais com a ideia de maior disseminação das mesmas no futuro como

Rev. de Direito, Economia e Desenvolvimento Sustentável | e-ISSN: 2526-0057| Goiânia| v. 5 | n. 1 | p. 57-76| 
meio de pagamento também pode ser considerada como uma concorrência potencial para os Bancos.

Assim, condutas praticadas por agentes para impedir ou dificultar o acesso de concorrentes ao mercado, configuram-se infrações à ordem econômica. Independentemente de qualquer justificativa quanto ao desconhecimento acerca da origem de recursos dos clientes das corretoras, os bancos devem analisar individualmente se cada corretora adotou, além de outras medidas, práticas preventivas contra a "lavagem de dinheiro". Outrossim, não se pode prejudicar a atuação de empresas nascentes pelo simples fato da matéria ainda não ter sido regulada pelo Órgão competente, pois isto iria contra até mesmo o Princípio da Livre Iniciativa, na medida em que desestimularia novos investimentos em inovações.

Faz-se uma crítica, ainda, ao descompasso das decisões tomadas no âmbito judicial ao não levarem em conta questões referentes à concorrência, quando da análise de caso semelhante envolvendo Bancos e Corretoras. O melhor dos mundos seria a atuação conjunta do Órgão de defesa econômica e do Judiciário, fato que garantiria maior segurança jurídica e celeridade aos processos.

\section{REFERÊNCIAS}

OCDE. Working Party No. 2 on Competition and Regulation - Hearing on Disruptive Innovation in the Financial Sector - Note by the Secretariat. 2015. Disponível em:<http://www.oecd.org/officialdocuments/publicdisplaydocumentpdf/?cote=DAF/COMP/ WP2(2015)9\&doclanguage=en $>$. Acesso em: 01 de março de 2019.

BACEN. Perguntas Frequentes. 2017. Disponível em:<https://www.bcb.gov.br/pre/bc_atende/port/moedasvirtuais.asp?idpai=FAQCIDADAO\& frame=1\#2>. Acesso em: 02 de março de 2019.

BACEN. Comunicado n. 31.379, de 16 de novembro de 2017. Disponível em:<https://www.bcb.gov.br/estabilidadefinanceira/exibenormativo?tipo=Comunicado\&num ero=31379>. Acesso em: 15 de março de 2019.

BACEN. Prevenção à lavagem de dinheiro e ao financiamento do terrorismo. Disponível em:<https://www.bcb.gov.br/estabilidadefinanceira/lavagemdinheiro>. Acesso em: $17 \mathrm{de}$ março de 2019.

BRASIL. Lei 12.529, de 30 de novembro de 2011. Disponível em:< http://www.planalto.gov.br/ccivil_03/_Ato2011-2014/2011/Lei/L12529.htm>. Acesso em: 05 de março de 2019. 
BRASIL. Constituição Federal de 1988. Disponível em:< http://www.planalto.gov.br/ccivil_03/Constituicao/Constituicao.htm>. Acesso em 02 de março de 2019.

CADE. Guia de Compliance. 2016. Disponível em:<http://www.cade.gov.br/acesso-ainformacao/publicacoes-institucionais/guias_do_Cade/guia-compliance-versao-oficial.pdf $>$. Acesso em: 12 de março de 2019.

CADE. Nota Técnica n. 39/2018/CGAA2/SGA1/SG/CADE. 2018. Disponível em:< https://sei.cade.gov.br/sei/modulos/pesquisa/md_pesq_documento_consulta_externa.php?DZ2 uWeaYicbuRZEFhBtn3BfPLlu9u7akQAh8mpB9yOq_PAOpP9dDSgD6LArOomnyuCuxWvMxZXH0h_hNIMOX Vz24XbbZ7YVbHdLYBX85ikU5J-39JyCQbDhh5GXrOjb>. Acesso em: 02 de março de 2019.

CADE. Perguntas sobre infrações à ordem econômica. Disponível em: $<$ http://www.cade.gov.br/servicos/perguntas-frequentes/perguntas-sobre-infracoes-aordem-economica>. Acesso em 01 de março de 2019.

CANDELORO, Ana Paula P. Compliance $360^{\circ}$ : riscos, estratégias, conflitos e vaidades no mundo corporativo. São Paulo: Trevisan Editora Universitária, 2012.

FEBRABAN. 2018. Disponível em:<https://cmsportal.febraban.org.br/Arquivos/documentos/PDF/Inova\%C3\%A7\%C3\%A3o $\% 20 \mathrm{e} \% 20 \mathrm{Competi} \% \mathrm{C} 3 \% \mathrm{~A} 7 \% \mathrm{C} 3 \% \mathrm{~A} 3 \mathrm{o} \% 20$

$\% 20$ Novos\%20Caminhos\%20para\%20Redu\%C3\%A7\%C3\%A3o\%20dos\%20Spreads\%20Ba nc\%C3\%A1rios.PDF>. Acesso em: 10 de março de 2019.

FERREIRA, Marcelle Ragazoni Carvalho. A Importância da Livre Concorrência para o Desenvolvimento Econômico Brasileiro. Direito concorrencial: avanços e perspectivas Livro 1 / coordenação de João Grandino Rodas - 1.ed. - Curitiba: Editora Prismas, 2018. 540 p.; $23 \mathrm{~cm}$.

FIGUEIREDO, Leonardo Vizeu. Lições de direito econômico. 5. ed. Rio de Janeiro: Forense, 2012.

MANZONI, Leandro. 8 estabelecimentos brasileiros que aceitam bitcoin. 2018. Disponível em:<https://forbes.uol.com.br/negocios/2018/01/8-estabelecimentos-brasileiros-que-aceitambitcoin/\#foto8>. Acesso em 15 de março de 2019.

RECEITA FEDERAL. 2016. Disponível em:<http://receita.economia.gov.br/interface/cidadao/irpf/2016/perguntao/irpf2016perguntao. pdf $>$. Acesso em 27 de março de 2019.

STELLA, Julio Cesar. Moedas Virtuais no Brasil: como enquadrar as criptomoedas. Disponível em: 
<https://revistapgbc.bcb.gov.br/index.php/revista/issue/download/26/A9\%20V.11\%20$\% 20$ N.2>. Acesso em: 11 de março de 2019.

STJ. 2018. Disponível em: $<$ https://ww2.stj.jus.br/websecstj/cgi/revista/REJ.cgi/ATC?seq=87504469\&tipo=3\&nreg= $201702244334 \&$ SeqCgrmaSessao $=\&$ CodOrgaoJgdr $=\& d t=20181016 \&$ formato $=$ PDF $\&$ salvar $=$ false>. Acesso em 14 de março de 2018. 